\title{
Assessment of traditional and non- traditional risk factors for premature atherosclerosis in children with juvenile dermatomyositis and pediatric controls
}

Dawn M. Wahezi ${ }^{1 *}$ D, Emily J. Liebling ${ }^{1}$, Jaeun Choi $^{2}$, Marija Dionizovik-Dimanovski ${ }^{1}$, Qi Gao ${ }^{2}$ and Jillian Parekh ${ }^{1}$

\begin{abstract}
Background: Children with juvenile dermatomyositis (JDM), the most common inflammatory myopathy of childhood, may be at increased risk of premature atherosclerosis given a host of traditional and non-traditional risk factors. The primary aim of this study was to determine the underlying frequency of premature atherosclerosis in children with JDM compared to pediatric controls using flow-mediated dilation as a measure of endothelial function.

Methods: Children and adolescents with and without JDM were evaluated for traditional atherosclerotic risk factors and assessment of endothelial function, using Endothelial Pulse Amplitude Testing (Endo-PAT).

Results: In this study, $75 \%$ of pediatric controls were of Black or Hispanic descent (compared to $55 \%$ in the JDM group) and $70 \%$ were found to live in a household with a medium income less than $\$ 50,000 /$ year (compared to $45 \%$ in the JDM group). Among traditional atherogenic risk factors, lipoprotein A appeared to be different between controls and JDM patients $(66 \mathrm{nmol} / \mathrm{L}$ and $16.5 \mathrm{nmol} / \mathrm{L}$, respectively). Using a reactive hyperemia index $(\mathrm{RHI})<1.67$ as evidence of endothelial dysfunction, $75 \%$ of controls were defined as having endothelial dysfunction compared to $50 \%$ in JDM group. When controlled for lipoprotein A as an atherogenic confounder, JDM patients were found to have a $41 \%$ increase in $\mathrm{RHI}$, thus indicating less endothelial dysfunction compared to controls.

Conclusions: In this study, we have shown that atherogenic risk factors are present in the pediatric population and may be associated with endothelial dysfunction, even at very young ages. Despite increasing concerns that children with rheumatologic disorders may be at increased risk of developing premature atherosclerosis, traditional and sociodemographic features may play a greater role in the ultimate development of cardiovascular disease.
\end{abstract}

Keywords: Pediatric dermatomyositis, Cardiovascular disease, Premature atherosclerosis

* Correspondence: dwahezi@montefiore.org

${ }^{1}$ Children's Hospital at Montefiore, Bronx, NY, USA

Full list of author information is available at the end of the article

(c) The Author(s). 2020 Open Access This article is licensed under a Creative Commons Attribution 4.0 International License, which permits use, sharing, adaptation, distribution and reproduction in any medium or format, as long as you give appropriate credit to the original author(s) and the source, provide a link to the Creative Commons licence, and indicate if changes were made. The images or other third party material in this article are included in the article's Creative Commons licence, unless indicated otherwise in a credit line to the material. If material is not included in the article's Creative Commons licence and your intended use is not permitted by statutory regulation or exceeds the permitted use, you will need to obtain permission directly from the copyright holder. To view a copy of this licence, visit http://creativecommons.org/licenses/by/4.0/ The Creative Commons Public Domain Dedication waiver (http://creativecommons.org/publicdomain/zero/1.0/) applies to the data made available in this article, unless otherwise stated in a credit line to the data. 


\section{Background}

Cardiovascular disease (CVD) is a leading cause of morbidity and mortality in the adult population. There is increasing evidence to suggest that atherosclerosis begins in childhood, progresses silently for many years and only becomes apparent once clinical manifestations, including myocardial infarction and/or cerebrovascular accident, occur $[1,2]$. Children with rheumatologic disorders may be at increased risk of developing premature atherosclerosis due to both disease specific risk factors, such as chronic inflammation, corticosteroid burden, elevated homocysteine levels and underlying vasculopathy; as well as a host of traditional risk factors, including dyslipidemia, insulin resistance, obesity and hypertension [3-7]. Premature atherosclerosis has been demonstrated among young patients with systemic lupus erythematosus (SLE) and Kawasaki disease (KD), using non-invasive ultrasound techniques including carotid intima-media thickness (CIMT) and flow-mediated dilation (FMD) [4, 8]. This finding is not surprising given the evidence that atherosclerosis is, in large part, an inflammatory disorder initiated and propagated by both humoral and cellular immunity $[9,10]$.

Cardiovascular manifestations of juvenile dermatomyositis (JDM), the most common idiopathic inflammatory myopathy of childhood, include acquired structural abnormalities, ventricular dysfunction, arrhythmias, myocarditis, and hypertension [11-17], with myocardial infarction acting as a rare cause of death $[11,13,18,19]$. JDM shares the same atherogenic risk factors and vasculopathic features as those of other rheumatologic illnesses, with the added component of lipodystrophy and its related metabolic derangements [15, 20, 21]. Moreover, higher rates of traditional atherosclerotic risk factors have been reported in adult patients with idiopathic inflammatory myopathies as compared to the general population $[12,17,22]$.

A potential consequence of the systemic vasculopathy in JDM is endothelial dysfunction, a broad term denoting impaired vasodilation secondary to diminished production or availability of nitric oxide (NO) [9]. Recognized as an early physiologic precursor of atherosclerosis, endothelial dysfunction can long precede vessel structure changes, which allows it to serve as an independent predictor of future CVD $[9,23]$. Prior investigations of endothelial dysfunction in children have used non-invasive ultrasound techniques, such as brachial artery FMD and pulse wave velocity (PWV) as validated surrogate outcome markers of early atherosclerosis [20, 24]. These methods correlate with cardiovascular events and severity of coronary artery disease in adults, as confirmed by angiography [25-29]. Further substantiating these tools in children is the association between reduced FMD and the presence of atherogenic risk factors in pediatric patients with KD, familial hypercholesterolemia, type I diabetes mellitus (T1DM), and obesity [8, 30-36]. Despite significant advances in ultrasonographic technology, limitations surround its use, particularly in children [37]. Endothelial Pulse Amplitude Testing (Endo-PAT) is an FDA approved method of detecting endothelial dysfunction, that is inexpensive, noninvasive, reproducible, and operator independent. It assesses post-occlusive vasodilatory response in the digital arteries and serves as an accurate measure of endothelial function in both central and peripheral circulation in adults [38, 39].

There is a paucity of data regarding cardiovascular outcomes in children with JDM, and to date, premature atherosclerosis has not been evaluated in these patients. Identification of the earliest stages of the atherosclerotic process in patients with chronic inflammation is critical to the prevention of the long-term morbidity and mortality associated with CVD. The primary aim of this study was to determine the underlying frequency of premature atherosclerosis and atherogenic risk factors in children with JDM, as compared to pediatric controls, using flow-mediated dilation as a measure of endothelial function. The secondary aim was to evaluate the potential association of endothelial dysfunction with these atherogenic risk factors.

\section{Methods}

\section{Study participants and recruitment}

Children, adolescents, and young adults, age 2-22 years, with a diagnosis of probable or definite JDM, as determined by Bohan and Peter criteria, seen in the pediatric rheumatology clinic at the Children's Hospital at Montefiore (CHAM) from September 2014 to September 2016, were selected for inclusion in the study [40]. Retrospective clinical and laboratory information were obtained via chart review to determine disease specific characteristics including date of diagnosis, muscle enzymes, disease duration, medication usage, and disease manifestations (including calcinosis, lipodystrophy, skin ulcers, cardiopulmonary or gastrointestinal involvement). Pediatric controls included patients with no known co-existing chronic medical conditions, seen in the general pediatric clinic at the Family Care Center, Montefiore Medical Center. Controls were manually matched based on comparison to patients with JDM with regards to age, gender, race and body mass index (BMI), in an attempt to balance the groups. Exclusion criteria included (1) a diagnosis of chronic illness other than JDM (2) known CVD (3) current use of medication that alters lipid metabolism or endothelial function and (4) current smoking. Twenty matched pairs were recruited. Annual medium household income by zip-code was calculated for all participants using U.S. Census Bureau, 2012-2016 
American Community Survey. Values were categorized in increments of $\$ 25,000$ to allow for comparison. The study protocol and written informed consent procedures were approved by the Institutional Review Board of the Einstein Human Research Protection Program of the Albert Einstein College of Medicine - Montefiore Medical Center (Reference \# 11-10-376E).

\section{Atherosclerotic risk factor assessment}

Anthropometric assessments of all subjects were performed including weight, height, BMI, pulse rate, and blood pressure. Smoking history, personal and familial history of CVD, hypertension, and diabetes mellitus were obtained by demographic questionnaire. After an overnight fast, blood specimens were collected for the following evaluations: total cholesterol (TC), low-density lipoprotein (LDL), high-density lipoprotein (HDL), triglycerides (TG), insulin, glucose, hemoglobin A1C, highsensitivity C-reactive protein (hSCRP), lipoprotein A, homocysteine, apolipoprotein A1, and apolipoprotein B. Assessment of insulin resistance was performed using the Homeostatic Model Assessment for Insulin Resistance (HOMA-IR) with the following formula: HOMA$I R=$ fasting insulin $x$ fasting glucose $/ 22.5$ [41].

\section{JDM disease activity and severity assessments}

Additional disease specific laboratory evaluations were performed on subjects with JDM including creatine phosphokinase (CPK), lactate dehydrogenase (LDH), aspartate aminotransferase (AST), aldolase, and von-Willebrand factor (vWF) antigen. Values were determined to be normal based on local lab cutoffs. Validated disease activity measures for JDM were performed, including the Childhood Myositis Assessment Scale (CMAS, range 0-52) and Disease Activity Score (DAS, range 0-20), the latter assessing both muscle and skin components [42, 43]. Long-term damage was assessed using the International Myositis Assessment and Clinical Studies Group (IMACS) Myositis Damage Index (MDI), evaluated in this study using the extent of damage scoring system (potential range 0-35 in children age $<12$ years, $0-37$ in adolescents and $0-38$ in adults) $[44,45]$.

\section{Flow mediated dilation}

Endo-PAT. Assessment of endothelial function was performed in all patients using Endo-PAT (Itamar Medical Ltd., Caesarea, Israel), which combines features of traditional FMD with beat-to-beat plethysmographic recordings of digital arterial pulse wave amplitude using pneumatic probes. Subjects were required to avoid exercise, caffeine, and foods with high fat content one day prior to testing, and to engage in an eight hour overnight fast. Fingernails were trimmed to improve accuracy of the study. Prior to the onset of the study, patients rested comfortably on an examination bed in a warm room for $15 \mathrm{~min}$ to allow for a relaxed cardiovascular steady-state. Baseline pulse wave amplitude measurements at the distal tip of both index fingers were recorded over five minutes. To measure reactive hyperemia, the brachial artery of the right arm was occluded with a blood pressure cuff inflated to $40-60 \mathrm{mmHg}$ above systolic pressure for five minutes with continued recording. This was followed by rapid cuff deflation and subsequent fiveminute recording time. The contralateral arm served as the control for the entire pulse wave amplitude recording period. The Endo-PAT / reactive hyperemia index (RHI) was calculated using proprietary software: it is the ratio of the average post-occlusion pulse amplitude to the average pre-occlusion pulse amplitude baseline, multiplied by a baseline correction factor. Prior evaluation of discomfort associated with this procedure resulted in a median pain score of one on the Wong-Baker Faces Pain Scale [46].

Reduced values of RHI indicate a reduced reactive hyperemic response and thus increased likelihood of endothelial dysfunction. Values of RHI $<1.67$ were defined as evidence of endothelial dysfunction, as determined by Bonetti et al., to yield $82 \%$ sensitivity and $77 \%$ specificity in the identification of adult patients with coronary endothelial dysfunction [38]. Trials of Endo-PAT in children yielded a mean RHI of 1.78 in healthy subjects, as compared to 1.50 in the severely obese and 1.63 in T1DM, but no discrete parameters have yet been identified in the pediatric population $[32,46]$.

\section{Data analysis}

All data analyses were preceded by extensive checking and verification to identify and resolve reasons for missing data, inconsistencies, and out-of-range values. Descriptive analyses were performed on the demographic and clinical characteristics of study participants, variables related to JDM status (case/control) and endothelial function. Bivariate associations of categorical variables with JDM status were evaluated by the Chisquare or Fisher's exact test; and mean and median levels of continuous variables were estimated and compared between JDM patients and pediatric controls using the two-sample T-test or Wilcoxon rank sum test, as dictated by distribution of the data. Linear regression models were used to compare JDM patients and pediatric controls with respect to endothelial function measure (i.e. RHI). The outcome variable, RHI, was logtransformed due to non-normally distributed data and the results are reported as a ratio of RHI (i.e. percent change in RHI) for ease of interpretation. There was an issue of limited sample size which did not support a 
multivariable analysis adjusting for multiple risk factors together, and therefore exploratory analyses were performed through models individually constructed for each atherogenic risk factor uncorrected to assess for an interaction with JDM status on the outcome. Based on the results from the exploratory uncorrected tests, additional exploratory stratification by JDM status was conducted for the individual risk factors. Additional subgroup analysis of JDM patients was performed to evaluate the usage of medications on RHI by Wilcoxon rank sum tests due to limited sample sizes of medication groups and non-normality of the RHI data. $P$-value less than 0.05 was considered statistically significant. Data were analyzed by using SAS software (version 9.4; SAS Institute, Inc., Cary, NC).

\section{Results}

\section{Clinical characteristics of study participants}

Table 1 lists the demographic and clinical features of the study participants at the time of evaluation in this study. Overall, the mean age was $12.4 \pm 4.1$ years (range 6-22) with a female preponderance (70\%). Race and ethnicity were self-reported with $35 \%$ of total participants identifying as White, non-Hispanic, $20 \%$ as Black, nonHispanic and $45 \%$ as Hispanic. There were no statistically significant differences between groups with regards to age, gender, race or BMI; however, $55 \%$ of pediatric controls reported Hispanic ethnicity compared to $35 \%$ in the JDM group. Annual medium household income by zip-code was reviewed for each study participant; $70 \%$ of pediatric controls and $45 \%$ of JDM patients were found to live in a household with a medium income less than $\$ 50,000 /$ year (Fig. 1).

JDM patients had a median disease duration of 44 months [IQR: 27, 75] with minimal evidence of active disease and damage (median CMAS $=52$, range 47-52; median DAS 0, range 0-5; median MDI (extent) $=0$, range $0-3)$. CPK, LDH, AST and aldolase were normal in over 90\% of JDM patients (Table 2). Among the JDM patients, at the time of the study, 7 were currently on prednisone (35\%) (with doses ranging from $0.1-0.7 \mathrm{mg} / \mathrm{kg} /$ day), 13 on hydroxychloroquine (65\%), 15 on methotrexate $(75 \%)$ and 9 on IVIG (45\%). None of the JDM patients had previously known cardiovascular disease.

Table 1 Clinical and laboratory data in JDM patients and pediatric controls $(n=40)^{a}$

\begin{tabular}{|c|c|c|c|c|}
\hline & Total $(n=40)$ & Pediatric controls $(n=20)$ & JDM patients $(n=20)$ & $p$-value \\
\hline Age (years) & $12.4 \pm 4.1$ & $12.7 \pm 3.9$ & $12.1 \pm 4.4$ & 0.651 \\
\hline Female gender & $28(70 \%)$ & $14(70 \%)$ & $14(70 \%)$ & $>0.999$ \\
\hline Race & & & & 0.392 \\
\hline White, non-Hispanic & $14(35 \%)$ & $5(25 \%)$ & $9(45 \%)$ & \\
\hline Black, non-Hispanic & $8(20 \%)$ & $4(20 \%)$ & $4(20 \%)$ & \\
\hline Hispanic & $18(45 \%)$ & $11(55 \%)$ & $7(35 \%)$ & \\
\hline $\mathrm{BMI}$ & $20.9 \pm 5$ & $20.9 \pm 4.9$ & $21 \pm 5.1$ & 0.950 \\
\hline BMI category & & & & $>0.999$ \\
\hline Healthy & $24(60 \%)$ & $12(60 \%)$ & $12(60 \%)$ & \\
\hline Overweight/Obese & $16(40 \%)$ & $8(40 \%)$ & $8(40 \%)$ & \\
\hline Positive cardiac family history & $23(58 \%)$ & $12(60 \%)$ & $11(58 \%)$ & 0.894 \\
\hline Systolic blood pressure (mmHg) & $109.8 \pm 10.8$ & $106.9 \pm 10.5$ & $112.8 \pm 10.5$ & 0.081 \\
\hline Diastolic blood pressure (mmHg) & $66 \pm 7$ & $63.7 \pm 6.9$ & $68.4 \pm 6.6$ & 0.035 \\
\hline Total cholesterol (mg/dL) & $159.1 \pm 32.9$ & $163.1 \pm 29.1$ & $154.8 \pm 36.7$ & 0.441 \\
\hline $\mathrm{LDL}(\mathrm{mg} / \mathrm{dL})$ & $87.6 \pm 25.5$ & $92.8 \pm 23.5$ & $82.3 \pm 27.0$ & 0.203 \\
\hline HOMA-IR & $2.1[1.4,3.1]$ & $2[1.7,2.8]$ & $2.1[1.2,3.3]$ & 0.922 \\
\hline Hemoglobin A1c & $5.5 \pm 0.3$ & $5.6 \pm 0.3$ & $5.4 \pm 0.3$ & 0.084 \\
\hline Lipoprotein A $(\mathrm{nmol} / \mathrm{L})^{c}$ & $46[14,87]$ & $66[24,91]$ & $16.5[10,70]$ & 0.055 \\
\hline Apolipoprotein B/A1 ratio & $0.5 \pm 0.1$ & $0.53 \pm 0.1$ & $0.46 \pm 0.1$ & 0.082 \\
\hline hsCRP (mg/L) & $0.2[0.1,0.7]$ & $0.3[0.2,0.8]$ & $0.2[0.1,0.4]$ & 0.178 \\
\hline $\mathrm{RHI}$ & $1.57[1.2,1.9]$ & $1.43[1.2,1.7]$ & $1.72[1.3,2.4]$ & 0.148 \\
\hline Abnormal $\mathrm{RHI}<1.67$ & $25(63 \%)$ & $15(75 \%)$ & $10(50 \%)$ & 0.103 \\
\hline $\log \mathrm{RHI}$ & $0.45 \pm 0.33$ & $0.36 \pm 0.24$ & $0.54 \pm 0.39$ & 0.089 \\
\hline
\end{tabular}

${ }^{a}$ Continuous variables expressed as mean \pm standard deviation or median [interquartile range]. Categorical variables expressed as frequency (percentages)

b Homeostatic Model Assessment for Insulin Resistance (HOMA-IR): HOMA-IR = fasting insulin $x$ fasting glucose / 22.5 [43]

c Only evaluated in 31 participants (17 pediatric controls and 14 JDM patients) 


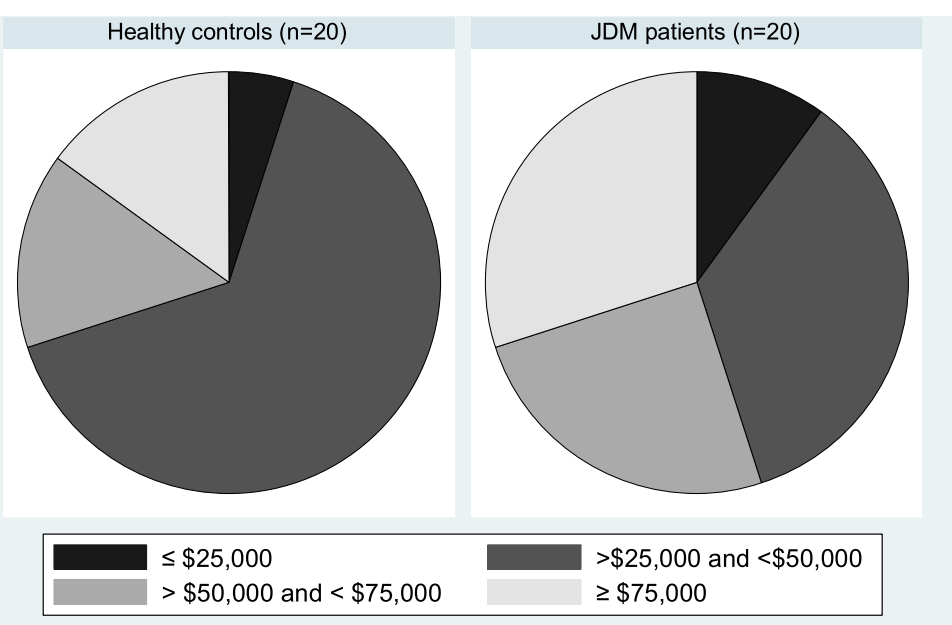

Fig. 1 Annual medium household income category in JDM patients versus pediatric controls

Bivariate analyses of endothelial function and atherogenic risk factors between JDM cases and pediatric controls

Among the total study population of pediatric controls and JDM patients, 63\% of participants had endothelial dysfunction (as defined by adult Endo-PAT cutoff < 1.67), with $75 \%$ in pediatric controls and 50\% in JDM patients (Table 1). Pediatric controls had lower median RHI than JDM patients $(1.43[1.2,1.7]$ versus $1.72[1.3,2.4]$ respectively) and higher endothelial dysfunction, however, these results were not significantly different between groups. In evaluation of atherogenic risk factors, patients with JDM had significantly higher diastolic blood pressure compared to pediatric controls $(p=0.035)$. Among traditional atherogenic risk factors, lipoprotein $\mathrm{A}$ appeared to be different with higher levels in pediatric controls than JDM patients $(66 \mathrm{nmol} / \mathrm{L}$ versus $16.5 \mathrm{nmol} / \mathrm{L}$ respectively; $p=0.055$ ) (Table 1 ).

\section{Exploratory univariate assessment of endothelial function in JDM}

The association of JDM status with endothelial function was evaluated using individual linear models controlling for potentially confounding atherogenic risk factors. JDM

Table 2 Disease activity assessment in JDM patients $(n=20)$

\begin{tabular}{lll}
\hline Measure of Disease Activity & Median $[I \mathrm{QR}]$ & $\begin{array}{l}\text { Patients with } \\
\text { normal values* }\end{array}$ \\
\hline CPK $(\mathrm{U} / \mathrm{L})$ & $95[71,153]$ & $19(95 \%)$ \\
LDH $(\mathrm{U} / \mathrm{L})$ & $213[176,243]$ & $19(95 \%)$ \\
AST $(\mathrm{U} / \mathrm{L})$ & $24[22,27]$ & $18(90 \%)$ \\
Aldolase $(\mathrm{U} / \mathrm{L})$ & $6.4[5.6,7.3]$ & $19(95 \%)$ \\
WWF antigen $(\%)$ & $119[72,149]$ & $12(63 \%)$ \\
CMAS & $52[50,52]$ & $13(65 \%)$ \\
DAS & $0[0,2]$ & $11(55 \%)$ \\
\hline
\end{tabular}

status appeared to be a significant predictor for increased RHI when controlled for lipoprotein A (Table 3, $p=$ 0.006 ) or hsCRP (Table $4, p=0.048$ ). More specifically, when controlled for lipoprotein A as an atherogenic confounder, JDM patients were found to have a $41 \%$ increase in reactive hyperemia index (RHI), thus indicating less endothelial dysfunction compared to pediatric controls. In addition, we conducted the model adjusting for both lipoprotein A and hsCRP, however, the Likelihood Ratio Test showed that the model controlling for lipoprotein A only is more appropriate than the bigger model controlling for both, which implies that lipoprotein $\mathrm{A}$ is the dominating confounder and that the role of hsCRP as a confounder is more pronounced without lipoprotein A. Therefore, the results from the individual models controlling for lipoprotein A or hsCRP are presented separately.

\section{Association between endothelial function and BMI}

The association of BMI and RHI was investigated by JDM status-stratified analyses due to a statistically significant interaction with BMI and JDM status on RHI $(p<0.0001)$. After stratification by JDM status, BMI was found to be a significant predictor of increased RHI in JDM patients $(p<0.0001)$, but not in pediatric controls $(p=0.334)$ (Table 5).

\section{Evaluation of endothelial function within JDM participants}

The majority of JDM patients showed minimal evidence of disease activity, as demonstrated by greater than $90 \%$

Table 3 Association between JDM status and endothelial function when controlling for lipoprotein $\mathrm{A}(n=31)$

\begin{tabular}{llll}
\hline & Ratio of RHI & $95 \% \mathrm{Cl}$ & $p$-value \\
\hline JDM status & 1.41 & $1.12,1.79$ & $\mathbf{0 . 0 0 6}$ \\
Lipoprotein A & 1.00 & $0.99,1.00$ & 0.218 \\
\hline
\end{tabular}


Table 4 Association between JDM status and endothelial function when controlling for hsCRP $(n=39)$

\begin{tabular}{llll}
\hline & Ratio of RHI & $95 \% \mathrm{Cl}$ & $p$-value \\
\hline JDM status & 1.24 & $1.00,1.52$ & $\mathbf{0 . 0 4 8}$ \\
hsCRP & 1.00 & $0.97,1.04$ & 0.996 \\
\hline
\end{tabular}

with normal muscle enzymes, median CMAS $=52$ and median DAS $=0$. Eight patients were found to have both a CMAS $=52$ and DAS $=0$. Among these patients, 3 (37.5\%) were found to have an abnormal $\mathrm{RHI}<1.67$ compared to $7(58.3 \%)$ of the JDM patients with either an abnormal CMAS or DAS, however these results were not statistically significant $(p=0.650)$. There were no statistically significant differences in RHI with regards to MDI or when comparing current medication usage with those off the respective medication including prednisone, hydroxychloroquine, methotrexate, IVIG.

\section{Discussion}

Children with JDM, similar to other rheumatic diseases, may be at increased risk of premature atherosclerosis due to a host of traditional and non-traditional atherogenic risk factors. Typical contributing factors to poor outcomes in JDM include younger age at presentation, high initial serum CPK, longer disease duration, and complications including calcinosis and lipodystrophy [47]. It is unknown, however, to what extent these contribute to cardiovascular prognosis. To our knowledge, this is the first study to evaluate the frequency of premature atherosclerosis, as measured by endothelial dysfunction, in a racially diverse pediatric population with JDM.

Although there are no prior studies examining the prevalence of premature atherosclerosis in children with JDM, two small case-control studies have been performed assessing the cardiovascular outcomes of patients with history of JDM in childhood. The first involved 59 patients with JDM (mean age 16.8, range 238 years), in which a higher prevalence of hypertension and ventricular diastolic dysfunction was seen as compared to healthy age- and gender- matched controls [16]. In this study, a significant association was found between cardiac dysfunction and early disease activity (one-year post diagnosis). A second pilot study found increased cardiovascular risk factors and evidence suggestive of premature atherosclerosis in 8 adults with a prior history of JDM (median age: 38 years old), as compared

Table 5 Association between BMI and RHI in patients stratified by JDM status

\begin{tabular}{cccccccc}
\hline & \multicolumn{3}{c}{ JDM patients $(\boldsymbol{n}=20)$} & & \multicolumn{3}{c}{ Pediatric controls $(\boldsymbol{n}=20)$} \\
\cline { 2 - 3 } & Ratio of RHI & $95 \% \mathrm{Cl}$ & $p$-value & & Ratio of RHI & $95 \% \mathrm{Cl}$ & $p$-value \\
\hline BMI & 1.06 & $1.04,1.09$ & $<\mathbf{0 . 0 0 0 1}$ & & 0.99 & $0.97,1.01$ & 0.334 \\
\hline
\end{tabular}

to healthy controls. In this study, the adult patients with a history of JDM exhibited increased atherogenic risk factors (including higher blood pressure, lower adiponectin, less upper arm fat and increased proinflammatory oxidized HDL), as well as significantly increased CIMT and decreased FMD, as compared to healthy controls [48].

In our study, we found a statistically significant difference in endothelial function between JDM patients and pediatric controls when controlled for hsCRP or lipoprotein A, whereas our population of pediatric controls appeared to demonstrate a reduced post-occlusive hyperemic response (i.e. reduced RHI), and thus worse endothelial function, as compared to JDM patients. Although of borderline statistical significance, pediatric controls appeared to have higher levels of lipoprotein A, one of traditional atherogenic risk factors, which was an important confounder in our results. Lipoprotein A, independent of other lipids, has been associated with abnormal FMD and is an independent risk factor for premature atherosclerosis by causing impaired endothelium-dependent vasodilation of angiographically normal coronary arteries $[31,49,50]$. Similarly, hsCRP which was slightly higher in control patients was a confounder in the association between JDM status and endothelial dysfunction. This raises that question of whether the true inflammatory burden in JDM may be less than that of other rheumatic diseases (such as SLE) or whether achieving adequate disease control (as was seen in our patient sample), impacts overall endothelial function.

Interestingly, BMI was positively associated with RHI only in the JDM cohort, implying better endothelial function in the overweight/obese patients. This finding could possibly be explained by the potential beneficial effects that corticosteroids may have had on the vascular endothelium in JDM patients, while simultaneously contributing to their increasing BMI. A recent study highlights the conflicting impact that corticosteroids may have on endothelial function in patients with inflammatory diseases; whereas direct deleterious effects on the endothelium may be seen, these may be outweighed by the positive impact of reducing vascular inflammation [51]. We speculate that in the JDM patients, BMI was likely elevated due to a known side effect of steroid toxicity. Therefore, JDM patients with increasing BMI may have been simultaneously benefiting from reduced vascular inflammation and potentially reduced endothelial dysfunction. This theory may be supported by the fact that the majority of our JDM patients demonstrated minimal evidence of disease activity at the time of the study. In contrast, in control subjects, BMI was not found to be protective and may represent a group of patients with dietary/familial induced obesity and thus potentially increased traditional atherosclerotic risk factors. 
An additional consideration in the interpretation of our results is the impact that race, income and social disparities have on chronic disease and future comorbidities. The participants in this study primarily represent a population of Black and Hispanic youth from low income households in an inner-city clinic. Previous studies have demonstrated that racial and ethnic disparities are associated with worse morbidity and adult outcomes in children with chronic disease, including JDM [52-54]. Although it is difficult to apply adult cutoffs to children, in this study, $63 \%$ of our total group demonstrated endothelial dysfunction based on the adult RHI cutoff of 1.67 . Similarly, the median $\mathrm{RHI}=1.57$ in our overall study population is lower than previously described in healthy adolescents (1.78) and children with TIDM (1.63) [32, 46]. In our study, over half of pediatric controls were from a minority racial/ethnic background and a majority from a household with a medium income of less than $\$ 50,000$ per year. Due to the rarity of disease, families of children with JDM often travel from further distances to seek a specialized academic center and therefore were more likely to represent a racially and financially diverse population in our sample. Put together, these findings raise concern for the risk of endothelial dysfunction in young children, particularly across varying racial and socioeconomic groups. To what extent each of the proposed risk factors (traditional versus sociodemographic versus disease specific) play in the ultimate development of CVD is yet to be determined.

There are several limitations of this work that need to be overcome in further studies. First, the sample size was restricted due to the rarity of JDM, and thus multiple confounding risk factors could not be adjusted for together in a single multivariable analysis, which lacks generalizability of these results. It is also noted that although Endo-PAT is designed to detect the earliest signs of endothelial dysfunction, its prior use in very young children is limited. The feasibility of this test is dependent on cooperation of the child with minimal movement of the extremities during the course of the examination; any movements may have created artifact that could have altered the findings of this study. The Endo-PAT RHI calculation is specifically designed to correct for any detected artifact to assure the validity of the results. To address this concern more diligently, all study reports were examined by the manufacturer for quality assurance.

\section{Conclusions}

With progress in the treatment of rheumatologic diseases rapidly advancing, life expectancy has greatly improved, making complications of premature atherosclerosis a potential cause of morbidity and mortality in these patients. In this study, we have shown that atherogenic risk factors are present in the pediatric population and may be associated with endothelial dysfunction, even at very young ages. However, despite increasing concerns that children with rheumatologic disorders may be at increased risk of developing premature atherosclerosis, traditional and sociodemographic features may play a greater role in the ultimate development of cardiovascular disease. Increased awareness of premature atherosclerotic disease in all young children will allow for increased surveillance of modifiable atherogenic risk factors (both traditional and non-traditional) and the optimization of long-term clinical care.

\section{Abbreviations}

JDM: Juvenile dermatomyositis; CVD: Cardiovascular disease; SLE: Systemic lupus erythematosus; KD: Kawasaki disease; CIMT: Carotid intima-media thickness; FMD: Flow-mediated dilation; Endo-PAT: Endothelial Pulse Amplitude Testing; T1DM: Type I diabetes mellitus; BMI: Body mass index; TC: Total cholesterol; LDL: Low-density lipoprotein; HDL: High-density lipoprotein; TG: Triglycerides; hsCRP: High-sensitivity C-reactive protein; HOMA-

IR: Homeostatic Model Assessment for Insulin Resistance; CPK: Creatine phosphokinase; LDH: Lactate dehydrogenase; AST: Aspartate aminotransferase; VWF: Von-Willebrand factor; CMAS: Childhood Myositis Assessment Scale; DAS: Disease Activity Score; MDI: Myositis Damage Index; RHI: Reactive hyperemia index; CARRA: Childhood Arthritis and Rheumatology Research Alliance

\section{Acknowledgements}

The authors wish to acknowledge the Cure JM Foundation, Childhood Arthritis and Rheumatology Research Alliance (CARRA) and the ongoing Arthritis Foundation financial support of CARRA.

\section{Authors' contributions}

The final manuscript has been seen and approved by all listed authors and given necessary attention to ensure the integrity of the work. Study design (DW, JP, EL), data collection (DW, MD, JP), analysis (DW, JC, QG), interpretation (DW, JC, QG, JP, EL, MD), manuscript preparation (DW, EL, JP, $\mathrm{MD}, \mathrm{JC}, \mathrm{QG})$.

\section{Funding}

Cure JM Early Investigator Award, Childhood Arthritis and Rheumatology Research Alliance (CARRA).

\section{Availability of data and materials}

The datasets used and/or analyzed during the current study are available from the corresponding author on reasonable request.

\section{Ethics approval and consent to participate}

We confirm that this work is original and has not been published elsewhere, nor is it currently under consideration for publication elsewhere. The study protocol and written informed consent procedures were approved by the Institutional Review Board of the Einstein Human Research Protection Program of the Albert Einstein College of Medicine - Montefiore Medical Center (Reference \# 11-10-376E).

\section{Consent for publication}

N/A

\section{Competing interests}

The authors declare that they have no competing interests.

\section{Author details}

${ }^{1}$ Children's Hospital at Montefiore, Bronx, NY, USA. ${ }^{2}$ Albert Einstein College of Medicine, Bronx, NY, USA. 
Received: 18 November 2019 Accepted: 2 March 2020

Published online: 18 March 2020

\section{References}

1. Berenson GS, Srinivasan SR, Bao W, Newman WP 3rd, Tracy RE, Wattigney WA. Association between multiple cardiovascular risk factors and atherosclerosis in children and young adults. The Bogalusa heart study. $\mathrm{N}$ Engl J Med. 1998;338(23):1650-6.

2. Newman WP 3rd, Wattigney W, Berenson GS. Autopsy studies in United States children and adolescents. Relationship of risk factors to atherosclerotic lesions. Ann N Y Acad Sci. 1991;623:16-25.

3. Boros CA, Bradley TJ, Cheung MM, Bargman JM, Russell JL, McCrindle BW, et al. Early determinants of atherosclerosis in paediatric systemic lupus erythematosus. Clin Exp Rheumatol. 2011;29(3):575-81.

4. Schanberg LE, Sandborg C, Barnhart HX, Ardoin SP, Yow E, Evans GW, et al. Premature atherosclerosis in pediatric systemic lupus erythematosus: risk factors for increased carotid intima-media thickness in the atherosclerosis prevention in pediatric lupus erythematosus cohort. Arthritis Rheum. 2009;60(5):1496-507.

5. Soep JB, Mietus-Snyder M, Malloy MJ, Witztum JL, von Scheven E. Assessment of atherosclerotic risk factors and endothelial function in children and young adults with pediatric-onset systemic lupus erythematosus. Arthritis Rheum. 2004;51(3):451-7.

6. Chow PC, Ho MH, Lee TL, Lau YL, Cheung YF. Relation of arterial stiffness to left ventricular structure and function in adolescents and young adults with pediatric-onset systemic lupus erythematosus. J Rheumatol. 2007;34(6): 1345-52.

7. Nascif AK, Hilario MO, Terreri MT, Ajzen SA, D'Almeida V, Plavnik FL, et al. Endothelial function analysis and atherosclerotic risk factors in adolescents with systemic lupus erythematosus. Int J Adolesc Med Health. 2007;19(4): 497-505.

8. Huang SM, Weng KP, Chang JS, Lee WY, Huang SH, Hsieh KS. Effects of statin therapy in children complicated with coronary arterial abnormality late after Kawasaki disease: a pilot study. Circ J. 2008;72(10):1583-7.

9. Zhang C. The role of inflammatory cytokines in endothelial dysfunction. Basic Res Cardiol. 2008;103(5):398-406.

10. Frostegard J. Atherosclerosis in patients with autoimmune disorders. Arterioscler Thromb Vasc Biol. 2005;25(9):1776-85.

11. Pachman LM, Cooke N. Juvenile dermatomyositis: a clinical and immunologic study. J Pediatr. 1980;96(2):226-34.

12. Van Gelder $\mathrm{H}$, Charles-Schoeman $\mathrm{C}$. The heart in inflammatory myopathies. Rheum Dis Clin N Am. 2014;40(1):1-10.

13. Rai SK, Choi HK, Sayre EC, Avina-Zubieta JA. Risk of myocardial infarction and ischaemic stroke in adults with polymyositis and dermatomyositis: a general population-based study. Rheumatology (Oxford). 2016;55(3):461-9.

14. Silverberg Jl, Kwa L, Kwa MC, Laumann AE, Ardalan K. Cardiovascular and cerebrovascular comorbidities of juvenile dermatomyositis in US children: an analysis of the National Inpatient Sample. Rheumatology (Oxford). 2018 57(4):694-702

15. Coyle K, Rother Kl, Weise M, Ahmed A, Miller FW, Rider LG. Metabolic abnormalities and cardiovascular risk factors in children with myositis. J Pediatr. 2009;155(6):882-7.

16. Schwartz T, Sanner H, Husebye T, Flato B, Sjaastad I. Cardiac dysfunction in juvenile dermatomyositis: a case-control study. Ann Rheum Dis. 2011;70(5): 766-71.

17. Schwartz T, Diederichsen LP, Lundberg IE, Sjaastad I, Sanner H. Cardiac involvement in adult and juvenile idiopathic inflammatory myopathies. RMD Open. 2016;2(2):e000291.

18. Lundberg IE. The heart in dermatomyositis and polymyositis. Rheumatology (Oxford). 2006;45(Suppl 4):iv18-21.

19. Sullivan DB, Cassidy JT, Petty RE. Dermatomyositis in the pediatric patient. Arthritis Rheum. 1977;20(2 Suppl):327-31.

20. Barsalou J, Bradley TJ, Silverman ED. Cardiovascular risk in pediatric-onset rheumatological diseases. Arthritis Res Ther. 2013;15(3):212.

21. Bingham A, Mamyrova G, Rother Kl, Oral E, Cochran E, Premkumar A, et al. Predictors of acquired lipodystrophy in juvenile-onset dermatomyositis and a gradient of severity. Medicine (Baltimore). 2008;87(2):70-86.

22. Linos E, Fiorentino D, Lingala B, Krishnan E, Chung L. Atherosclerotic cardiovascular disease and dermatomyositis: an analysis of the Nationwide inpatient sample survey. Arthritis Res Ther. 2013;15(1):R7.
23. Szmitko PE, Wang CH, Weisel RD, de Almeida JR, Anderson TJ, Verma S. New markers of inflammation and endothelial cell activation: part I. Circulation. 2003;108(16):1917-23.

24. Slyper $\mathrm{AH}$. Clinical review 168: what vascular ultrasound testing has revealed about pediatric atherogenesis, and a potential clinical role for ultrasound in pediatric risk assessment. J Clin Endocrinol Metab. 2004;89(7):3089-95.

25. Lieberman EH, Gerhard MD, Uehata A, Selwyn AP, Ganz P, Yeung AC, et al. Flow-induced vasodilation of the human brachial artery is impaired in patients <40 years of age with coronary artery disease. Am J Cardiol. 1996;78(11):1210-4.

26. Neunteufl T, Katzenschlager R, Hassan A, Klaar U, Schwarzacher S, Glogar D, et al. Systemic endothelial dysfunction is related to the extent and severity of coronary artery disease. Atherosclerosis. 1997;129(1):111-8.

27. Bots ML, Hoes AW, Koudstaal PJ, Hofman A, Grobbee DE. Common carotid intima-media thickness and risk of stroke and myocardial infarction: the Rotterdam study. Circulation. 1997;96(5):1432-7.

28. Chambless LE, Heiss G, Folsom AR, Rosamond W, Szklo M, Sharrett AR, et al. Association of coronary heart disease incidence with carotid arterial wall thickness and major risk factors: the atherosclerosis Risk in communities (ARIC) study, 1987-1993. Am J Epidemiol. 1997;146(6):483-94.

29. O'Leary DH, Polak JF, Kronmal RA, Manolio TA, Burke GL, Wolfson SK Jr. Carotid-artery intima and media thickness as a risk factor for myocardial infarction and stroke in older adults. Cardiovascular health study collaborative research group. N Engl J Med. 1999;340(1):14-22.

30. de Jongh S, Lilien MR, Bakker HD, Hutten BA, Kastelein JJ, Stroes ES. Family history of cardiovascular events and endothelial dysfunction in children with familial hypercholesterolemia. Atherosclerosis. 2002;163(1):193-7.

31. Sorensen KE, Celermajer DS, Georgakopoulos D, Hatcher G, Betteridge DJ, Deanfield JE. Impairment of endothelium-dependent dilation is an early event in children with familial hypercholesterolemia and is related to the lipoprotein(a) level. J Clin Invest. 1994;93(1):50-5

32. Haller MJ, Stein J, Shuster J, Theriaque D, Silverstein J, Schatz DA, et al. Peripheral artery tonometry demonstrates altered endothelial function in children with type 1 diabetes. Pediatr Diabetes. 2007;8(4):193-8.

33. Mahmud FH, Earing MG, Lee RA, Lteif AN, Driscoll DJ, Lerman A. Altered endothelial function in asymptomatic male adolescents with type 1 diabetes. Congenit Heart Dis. 2006;1(3):98-103.

34. Tounian P, Aggoun Y, Dubern B, Varille V, Guy-Grand B, Sidi D, et al. Presence of increased stiffness of the common carotid artery and endothelial dysfunction in severely obese children: a prospective study. Lancet. 2001;358(9291):1400-4.

35. Ikemoto $Y$, Ogino $H$, Teraguchi M, Kobayashi $Y$. Evaluation of preclinical atherosclerosis by flow-mediated dilatation of the brachial artery and carotid artery analysis in patients with a history of Kawasaki disease. Pediatr Cardiol. 2005;26(6):782-6.

36. Kadono T, Sugiyama H, Hoshiai M, Osada M, Tan T, Naitoh A, et al. Endothelial function evaluated by flow-mediated dilatation in pediatric vascular disease. Pediatr Cardiol. 2005;26(4):385-90.

37. Corretti MC, Anderson TJ, Benjamin EJ, Celermajer D, Charbonneau F, Creager MA, et al. Guidelines for the ultrasound assessment of endothelialdependent flow-mediated vasodilation of the brachial artery: a report of the international brachial artery reactivity task force. J Am Coll Cardiol. 2002; 39(2):257-65.

38. Bonetti PO, Pumper GM, Higano ST, Holmes DR Jr, Kuvin JT, Lerman A. Noninvasive identification of patients with early coronary atherosclerosis by assessment of digital reactive hyperemia. J Am Coll Cardiol. 2004;44(11): 2137-41.

39. Kuvin JT, Patel AR, Sliney KA, Pandian NG, Sheffy J, Schnall RP, et al. Assessment of peripheral vascular endothelial function with finger arterial pulse wave amplitude. Am Heart J. 2003;146(1):168-74.

40. Bohan A, Peter JB. Polymyositis and dermatomyositis (first of two parts). N Engl J Med. 1975;292(7):344-7.

41. Radziuk J. Insulin sensitivity and its measurement: structural commonalities among the methods. J Clin Endocrinol Metab. 2000;85(12):4426-33.

42. Bode RK, Klein-Gitelman MS, Miller ML, Lechman TS, Pachman LM. Disease activity score for children with juvenile dermatomyositis: reliability and validity evidence. Arthritis Rheum. 2003;49(1):7-15.

43. Lovell DJ, Lindsley CB, Rennebohm RM, Ballinger SH, Bowyer SL, Giannini $\mathrm{EH}$, et al. Development of validated disease activity and damage indices for the juvenile idiopathic inflammatory myopathies. II. The childhood myositis assessment scale (CMAS): a quantitative tool for the evaluation of muscle 
function. The juvenile Dermatomyositis disease activity collaborative study group. Arthritis Rheum. 1999;42(10):2213-9.

44. Isenberg DA, Allen E, Farewell V, Ehrenstein MR, Hanna MG, Lundberg IE, et al. International consensus outcome measures for patients with idiopathic inflammatory myopathies. Development and initial validation of myositis activity and damage indices in patients with adult onset disease. Rheumatology (Oxford). 2004;43(1):49-54.

45. Rider LG, Lachenbruch PA, Monroe JB, Ravelli A, Cabalar I, Feldman BM, et al. Damage extent and predictors in adult and juvenile dermatomyositis and polymyositis as determined with the myositis damage index. Arthritis Rheum. 2009:60(11):3425-35.

46. Selamet Tierney ES, Newburger JW, Gauvreau K, Geva J, Coogan E, Colan SD, et al. Endothelial pulse amplitude testing: feasibility and reproducibility in adolescents. J Pediatr. 2009;154(6):901-5.

47. Pachman LM, Abbott K, Sinacore JM, Amoruso L, Dyer A, Lipton R, et al. Duration of illness is an important variable for untreated children with juvenile dermatomyositis. J Pediatr. 2006;148(2):247-53.

48. Eimer MJ, Brickman WJ, Seshadri R, Ramsey-Goldman R, McPherson DD, Smulevitz B, et al. Clinical status and cardiovascular risk profile of adults with a history of juvenile dermatomyositis. J Pediatr. 2011;159(5):795-801.

49. Ioka T, Tasaki H, Yashiro A, Yamashita K, Ozumi K, Tsutsui M, et al. Association between plasma lipoprotein(a) and endothelial dysfunction in normocholesterolemic and non-diabetic patients with angiographically normal coronary arteries. Circ J. 2002;66(3):267-71.

50. Emerging Risk Factors C, Erqou S, Kaptoge S, Perry PL, Di Angelantonio E, Thompson A, et al. Lipoprotein(a) concentration and the risk of coronary heart disease, stroke, and nonvascular mortality. JAMA. 2009;302(4):412-23.

51. Verhoeven F, Prati C, Maguin-Gate K, Wendling D, Demougeot C.

Glucocorticoids and endothelial function in inflammatory diseases: focus on rheumatoid arthritis. Arthritis Res Ther. 2016;18(1):258.

52. Phillippi K, Hoeltzel M, Byun Robinson A, Kim S. Race, Income, and Disease Outcomes in Juvenile Dermatomyositis. J Pediatr. 2017;184:38-44 e1.

53. Shonkoff JP, Garner AS. The lifelong effects of early childhood adversity and toxic stress. Pediatrics. 2012;129(1):e232-46.

54. Rubinstein TB, Mowrey WB, llowite NT, Wahezi DM. Delays to Care in Pediatric Lupus Patients: data from the childhood arthritis and rheumatology research Alliance legacy registry. Arthritis Care Res. 2018;70(3):420-7.

\section{Publisher's Note}

Springer Nature remains neutral with regard to jurisdictional claims in published maps and institutional affiliations.

Ready to submit your research? Choose BMC and benefit from:

- fast, convenient online submission

- thorough peer review by experienced researchers in your field

- rapid publication on acceptance

- support for research data, including large and complex data types

- gold Open Access which fosters wider collaboration and increased citations

- maximum visibility for your research: over $100 \mathrm{M}$ website views per year

At $\mathrm{BMC}$, research is always in progress.

Learn more biomedcentral.com/submissions 